REINHARD BRANDT

INSTITUTO DE FILOSOFIA

UNIVERSidad PHILIPPS, MARgurgo

En Kant no se habla de una "institución política", por lo que no se puede escribir un ensayo sobre este tema utilizando como hilo conductor sus propios conceptos. El concepto de institución aparece en sus escritos probablemente una sola vez, $y$, por cierto, en sentido metafórico: "Se puede mirar la crítica de la razón pura como el verdadero tribunal para todas las controversias de esta facultad, pues no tiende a mezclarse en estas disputas que recaen sobre los objetos, sino que es puesta para determinar y juzgar los derechos de la razón en general, según los principios de su institución primera" (A 751). ${ }^{1}$

La “institución" o “designación primera” (A 751) del tribunal de la razón pura divide, podemos extrapolar, a la historia entera en dos partes: acá el estado natural, allá el status civilis. En el primero reina el estado de guerra. "Así Hobbes afirma que el estado de naturaleza es un estado de injusticia y de violencia que debe necesariamente abandonarse para someterse a un poder legal que no limite nuestra libertad más que para hacerla compatible con la libertad de los demás y, por lo mismo, con el bien público." (A 752) En las tres instituciones que vamos a analizar más detenidamente, encontraremos de nuevo esta idea fundamental: el Estado, la Iglesia y la Universidad fundan, de acuerdo con la idea que las sustenta, un sistema de paz que organizan cada vez dentro de la "comunidad" [gemeinen Wesen], poniendo fin así al status naturalis. Sin embargo, al mismo tiempo se añade otro momento en estas instituciones, que si bien no está especificado en la exposición de la Crítica de la razón pura, sí es referido por Kant en el pasaje que sigue a los ya citados: "A esta libertad pertenece, pues, también la de someter al juicio público sus pensamientos y sus dudas cuando por sí mismo

1 La Crítica de la razón pura se cita según las ediciones A y B (de 1781 y 1787); el resto de las referencias de Kant corresponden a la edición de la Academia de las Ciencias de Berlín de 1900 y años posteriores. 
no pueda esclarecerlas, sin que por ello se juzgue al ciudadano inquieto y peligroso. Esto es lo que resulta del derecho primitivo de la razón humana..." De esta libertad tiene que "provenir todo perfeccionamiento del que nuestro estado es susceptible" (A 752). El juicio público conduce a un cambio de la condición misma del status civilis; las instituciones del Estado, la Iglesia y la Universidad son concebidas por Kant de tal modo que se encuentran, de acuerdo con principios específicos de la libertad, en un proceso histórico de ilustración. - No son instituciones completas, sino que están en sí mismas orientadas dinámicamente a un fin específico. Este pensamiento está ausente en la "institución" del tribunal de la razón pura. Estado, Iglesia y Universidad son concebidas como instituciones históricamente determinadas, y de tal modo que son concebidas dentro de una marcha en principio irreversible hacia lo mejor: las reglas de la propiedad en el Estado, por ejemplo, son presentadas, en una osada visión, como provisionales: cuando el contrato original "no abarca a todo el género humano, la adquisición seguirá siendo siempre provisional" (VI 266, 36-37; véase 350,6-12). También los estatutos de la Iglesia son provisionales (VI 121, 15; 176, 7); se irán adaptando gradualmente a la religión de la razón para ceder finalmente ante ella; la Universidad expone los dogmas de las Facultades superiores a la crítica enérgica de una filosofía ávida de verdad; y paulatinamente los téólogos, juristas y médicos hacen concesiones a la verdad y a la razón. El Estado, la Iglesia y la Universidad son concebidos dentro de la historia de la filosofía de tal modo que concluyen un status naturalis y se desarrollan dinámicamente, conforme a la idea que los sustenta, hacia su finalidad. Dado que la libertad del juicio público es el fermento de la aproximación del proceso hacia la idea rácional y hacia la finalidad, se le otorgará en Kant una especial atención al complejo de la libertad de opinión, en el marco de su concepción de las instituciones. Antes de dirigir nuestra atención a las instituciones y a la libertad de opinión, es necesario justificar por qué hablaremos del Estado, la Iglesia, la Universidad y la libertad de publicación bajo el título de "institución política".

Kant le dedicó publicaciones particulares a estos tres establecimientos o "instituciones", como denomina a la Iglesia; ${ }^{2}$ se ocupa del Estado en algunos ensayos histórico-filosóficos y principalmente en Principios metafisicos del derecho, de 1797; de la Iglesia prin-

2 Cfr. VI 327, 7-11 ("Debido a que también el ser de la Iglesia, el cual (como institución del culto divino público para el pueblo) debe ser cuidadosamente distinguido de la religión como convicción intima, la cual está totalmente fuera del alcance del poder civil..."); véase también VI 100, 6 y 24; Iglesia como "instituto": VI $369,8-9$ entre otros. 
cipalmente en el escrito La religión dentro de los límites de la mera razón, de 1793, y de la Universidad en El conflicto de las Facultades, de 1798. Con referencia a estos establecimientos habla siempre de una "comunidad": el Estado es la "comunidad política", la Iglesia la "comunidad ética" (VI 94, 19 entre otros) y la Universidad la "comunidad culta [gelehrt]" (VII 19, 21 entre otros). De este modo, la Iglesia y la Universidad también son "comunidades", "res publi$c a e^{n} \mathrm{u}$ organizaciones políticas. Son además políticas en tanto que el gobierno tiene interés en ellas, y esto, como se demostrará, por motivos exclusivamente políticos.

No hay en Kant una reflexión en torno a la relación de estas tres instituciones necesarias ${ }^{3}$ de presuntas ideas racionales, y sin embargo esta tríada no se basa en una ocurrencia arbitraria de Kant. Es decisivo para la teoría en su totalidad que derive sus estructuras fundamentales de una tradición profundamente enraizada en la historia europea. En el caso de la Universidad nos remontamos a Platón; la concepción de la Iglesia incorpora motivos de la tradición judeo-cristiana; la teoría del Estado se enlaza nuevamente con la antigua reflexión sobre la polis, la república y el derecho natural, principalmente en Platón y Cicerón.

La tríada Estado, Iglesia y Universidad se forma en la Edad Media. Conocida es la teoría de los dos poderes. El Papa Gelasius I le escribe al emperador bizantino Anastasio en el año 494: “ ${ }^{4}$ uo quippe sunt, quibus principaliter mundus hic regitur, auctoritas sacrata pontificum et regalis potestas". El sol y la luna simbolizan papado e imperio, Iglesia y Estado. Sin embargo, en el siglo XIII se propaga una nueva idea: Alejandro de Roes sostiene en su "Noticia seculi" que, según la voluntad de la Santísima Trinidad, hay tres "principados": sacerdotium, regnum y studium, y precisamente en los países europeos centrales Italia, Teutonia y Galia. El dominicano Tolomeo, alumno de Tomás de Aquino, agrega en su documento " $D e$

3 El hecho de que haya ideas racionales del Estado y de la Iglesia, ya está garantizado por, su función imprescindible en una metafísica de las costumbres y en una religión dentro de los límites de la mera razón; acerca de la idea racional de la Universidad, compárese VII $21,5 \mathrm{y}$ ss. ("Podemos admitir que todas las instituciones artificiales que se basan en una idea racional (como la del gobierno)..." ) -El que para Kant haya existido, en cierta forma, una relación entre las tres instituciones aquf expuestas, lo revela quizá un trabajo previo acerca de la filosofía del derecho: "NB. Sobre la comunidad civil, eclesiástica y culta..." (XXIII 352, 10).

4 Citado según H. Grundmann, Sacerdotium-Regnum-Studium. Zur Wertung der Wissenschaft im 19. Jahrhundert [Sobre lo evaluación de la ciencia en el riglo XIII], ahora en: H. Grundmann, Ausgewählte Aufoätze [Obras escogidas], 3a. parte: Bildung und Sprache [Cultura y lenguaje] (Monumenta Germanic Historica, Vol. 25, 3), Stuttgart, 1978, 275-291 (275). Me gufo aquí por los estudios de Grundmann. 
regimine principium": en toda monarquía existen tres "comitata": "Divinus cultus, sapientia scholastica et secularis potentia". ${ }^{5}$ No tenemos por qué exponer en particular la transmisión de esta figura; en este contexto basta la indicación de que Kant, sea cual fuere la fuente, la retoma y continúa. Cuando Alejandro de Roes habla de los tres principados como el fundamento, las paredes y el techo de la ecclesia, ${ }^{6}$ no es ésta simplemente una asociación subjetiva y una ocurrencia estética, sino una ánalogía con una forma arquitectónica primitiva, en la cual estos tres elementos son necesarios y suficientes; de este modo se sugieren una totalidad y un aislamiento sistemático y la tríada se justifica internamente hasta cierto punto. Esta representación, como una concepción asegurada en el orden del mundo, puede influir en la teoría de las instituciones hasta el siglo XVIII. Yo añado otro ejemplo -referente a la concepción de las instituciones sociales en Kant- de la relación directa, por no decir irreflexiva, que tienen con la tradición las ideas kantianas, que a la vez son las más modernas de su tiempo. En el ensayo de 1784 “QQué es la Ilustración?", dice: "Para esta Ilustración, sin embargo, no se requiere nada excepto la libertad; y precisamente la menos dañina de todas, aquella que sólo puede ser llamada libertad, a saber: la libertad de hacer uso público de su razón en forma cabal. Ahora, sin embargo, escucho por todos lados el llamado: ¡no razonen! El oficial dice: ¡No razonen, ejercítense! El consejero de finanzas: ¡No razonen, paguen! El clérigo: ¡No razonen, tengan fe! (Sólo una persona en el mundo dice: ¡Razonen todo lo que quieran y acerca de lo que quieran, pero obedezcan!)" (VIII 36, 34-37, 4). Por uso cabal de la propia razón entiende Kant el uso que hace de ésta el hombre culto; aquellos ciudadanos que tienen que obedecer las órdenes del oficial, del consejero de finanzas y del clérigo, harán un uso privado, no legítimo, de su razón en una disputa sobre la instrucción militar, el pago y la fe. La designación de estas tres instancias, a las que se une como cuarta el soberano - Federico II- parece a primera vista casual; sin embargo, tiene su fundamentación y sostén en la filosofía griega. La república platónica se divide, como es sabido, en tres estados: el inferior se ocupa de los bienes materiales, el medio se ocupa del propio cuerpo en el servicio militar, el superior se consagra a las tareas espirituales - precisamente conforme a esto se orienta la tríada de finanzas, ejército y espiritualidad en Kant. $\mathrm{Y}$ así como Platón agrega a las virtudes correspondientes a los tres estados una cuarta virtud cardinal - la justicia-, así se agrega acá el soberano a las otras tres funciones, para unir la libertad con la

5 Según Grundmann, loc. cit., 279.

6 Según Grundmann, loc. cit., $276^{4}$. 
obediencia. Volveremos a encontrarnos, durante la discusión de la institución de la Universidad, con la tríada de bienes materiales, cuerpo y alma: la Facultad de jurisprudencia se dedica a "la propiedad contingente" (VII 22, 11), la de medicina al cuerpo, y los teólogos se preocupan por el bienestar del alma. La cuarta, la Facultad de filosofía, insiste, sin sujeción a interés alguno, sólo en la verdad. $^{7}$

En la filosofía kantiana, y por lo tanto también en su "teoría de las instituciones", se encuentran íntimamente ligados entre sí, sin coacción alguna, el clasicismo y la modernidad. Kant piensa y escribe todavía más allá del umbral de la modernidad del siglo XIX; la técnica moderna, y la desestructuración de la sociedad propiciada o forzada por ella, da lugar al hecho de que los conceptos clásicos ya no permitan comprender los fenómenos sociales. Sin embargo, es justamente esta comprensión de la realidad la que debe posibilitar la teoría del Estado, la Iglesia y la Universidad en Kant: ésta está ciertamente orientada por la correspondiente idea de larazón dada a priori; sin embargo, explica los fenómenos reales de tal manera que éstos pueden ser reconocidos en el teorema, y este re-conocimiento contribuye a su adaptación con la idea original que los fundamenta. De esta manera, la "teoría de las instituciones" es, según Kant, eficiente en la práctica. Su publicidad es un elemento en el perfeccionamiento histórico con el cual están comprometidas las instituciones. En la base del Estado moderno, de la Iglesia moderna y de la Universidad moderna ya no hay ideas kantianas, y si se quiere aprender algo de la "teoría de las instituciones" de Kant, que está arraigada en el clasicismo, ello sólo se logrará por el camino indirecto del rompimiento y el extrañamiento históricos.

\section{El Estado}

La tríada de bienes materiales, cuerpo y alma, nos permite comprender tres diversas funciones del Estado que, en la tradición histórica, fueron entendidas y valorizadas de maneras distintas. Por un lado, el Estado puede ser concebido como una sociedad que tiene por objeto la solución conjunta de los problemas económicos; ésta es, probablemente, la idea de Rousseau cuando escribe que presupone que se celebra un contrato social, dado que los hombres en estado natural tropiezan con obstáculos que impiden su autoconservación, que exceden sus fuerzas individuales; el Estado surge, pues, con el

\footnotetext{
7 Acerca de la estructura general y la tradición de esta tríada, cfr. los estudios del autor en: Die Interpretation philosophischer Werke [La interpretación de obras filosóficas], Stuttgart, 1984.
} 
objeto de aliar las fuerzas de los individuos y dirigirlas en forma unificada. ${ }^{8}$ Según la segunda variante, el Estado surge de la lucha por los bienes materiales, de los que, en el estado natural, también puede formar parte el cuerpo de los otros hombres. La muerte violenta es el mal que pretenden evitar los hombres con la fundación del Estado. En tercer lugar, el objetivo del Estado puede consistir en posibilitar una conducción espiritual y moral de la vida (Platón, Aristóteles, Hegel). En la teoría moderna del derecho natural encontramos, en términos generales, la segunda variante en primer plano; particularmente, en Hobbes, la amenaza de la violencia inminente se convierte en el principio y el origen del "Leviatán", al cual tratan de incorporarse los hombres en la búsqueda de la propia protección. De acuerdo con esta segunda variante, el Estado es esencialmente un tribunal con leyes previamente promulgadas y que tiene la capacidad de imponer sanciones. Es decir, el origen del Estado en la segunda variante nos lleva a la teoría de los poderes: existe un poder legislativo, uno judicial y uno ejecutivo. Kant se pronuncia decididamente en contra de la teoría y de la práctica que surgen de la primera y la tercera variantes: el Estado no está facultado para hacer de los bienes económicos o morales y de la prosperidad material o intelectual y espiritual de sus ciudadanos el objeto de su obrar, sino que debe limitarse estrictamente a la realización del derecho y de la libertad analíticamente ligada al derecho. Como habrá de demostrarse posteriormente, únicamente puede interesarse de modo indirecto en el bienestar económico, físico y espiritual de sus ciudadanos.

Tanto el restablecimiento de la paz entre partidos y principios en conflicto, en general, como la teoría y la práctica del derecho público y privado, tienen un peso determinante en la filosofía kantiana, desde las publicaciones y notas más tempranas hasta los últimos escritos y reflexiones. ${ }^{9}$ La teoría dél derecho propiamente dicha, los Principios metafisicos de la teoría del derecho, se publican sólo después de prolongadas vacilaciones y renovados intentos en el año de 1797.

8 J. J. Rousseau, El contrato social, o Principios políticos del derecho (1762), I, 6.

- Hans Sauer nos da un panorama general en Kants Weg vom Krieg zum Frieden [El camino de Kant de la guerra a la paz] (Vol. I: "Widerstreit und Einheit" ["Antagonismo y unidad"]), Munich, 1967. Acerca de la época temprana, cfr. Ch. Ritter, Der Rechtsgedanke Kants nach den frühen Quellen (El pensamiento juridico de Kant según las fuentes tempranas], Francfort, 1971. No es sostenible la opinión de Ritter de que los Principios metafísicos de la teoría del derecho de 1797 sólo recordarían en el fondo los conceptos que ya eran trabajados a principios de los años 70 . 
La obra tardía de Kant fue publicada de tal manera que prácticamente excluye la comprensión de la estructura de su pensamiento, especialmente en cuanto al Estado y sus instituciones. Sin embargo, con base en una revisión del texto ${ }^{10}$ se consigue desprender la siguiente concepción como kantiana: la república está constituida, según la idea de la razón del Estado, por un poder legislativo que radica en el pueblo, o bien es determinado, en elección igualitaria, por los ciudadanos independientes. Esta potestas legislativa, el soberano, establece un gobierno que actúa autónomamente en un marco legislativo fijo, pero que puede ser destituido en caso de actuar en contra de las decisiones del poder legislativo. "El preceptor del pueblo (el legislador) no puede, pues, ser al mismo tiempo su gobernador; porque éste está sometido a la ley, es obligado por ella, y por consiguiente por otro: por el soberano. El soberano puede quitar al gobernador su poder, deponerlo, reformar su administración, pero no castigarlo..." (§ $42 \cdot \mathrm{L})^{11}$ "En fin, el que manda y el que gobierna no pueden juzgar, sino solamente instituir jueces como magistrados. El pueblo se juzga a sí mismo mediante aquellos de sus conciudadanos que son libremente elegidos como sus representantes; pero solamente en cada acto particular para el que han sido nombrados." ( $(49 \mathrm{~L})$ No existe poder judicial que esté a su vez sometido al poder legislativo (con respecto a la conformidad de las leyes con la constitución); sin embargo, lo siguiente es válido: "El gobernador actúa en lo particular de acuerdo con la voluntad general, pero el juez debe juzgar en casos controvertidos si éstos van de acuerdo con la voluntad general. El gobernador puede actuar injustamente” (Refl. 7752; XIX 507, 24-26).

La división de los poderes se desarrolla y fundamenta como sigue: "Cada ciudad encierra en sí tres poderes, es decir, la voluntad general unida en una triple persona (trias politica): el poder soberano (soberania) en la persona del legislador, el poder ejecutivo en la persona del gobierno (según la ley), y el poder judicial (como reconocimiento de lo Mío de cada cual según la ley) en la persona del juez (potestas legislatoria, rectoria et judiciaria), corresponden a las tres proposiciones de un razonamiento práctico: a la mayor, que contiene la Ley de aquella voluntad; a la menor, que contiene el precepto de conducta según la ley, es decir, el principio de la subordinación a la ley; y en fin, a la conclusión, que contiene la sentencia,

10 Véase la nueva edición de Bernd Ludwig, Hamburgo, 1986.

11 Los $\$ \S$ de la Teoría del derecho señalados con una " $L$ " se refieren a la edición de B. Ludwig. Acerca de la división sistemática del derecho en privado y público, confróntense las exposiciones de Ludwig en el Tomo Il de las Kant Porochungen [Investigaciones kantianas], Hamburgo, 1987 (de próxima aparíción). 
o lo que es de derecho en los diferentes casos" ( $\S 45 \mathrm{~L}) .{ }^{12}$ A esta estructura silogística corresponde el derecho privado, antepuesto al derecho público y fundamento de él, en su doctrina triádica: la teoría de la propiedad desarrolla las leyes generales -poseer algo externo como propio-, la teoría de la adquisición desarrolla la subordinación de las relaciones comerciales a las leyes, y el tercer capítulo, "De la adquisición subjetivamente condicionada" ( $\S 36-$ $\S 40 \mathrm{~L}$ ), ofrece la doctrina de las sentencias obligatorias, dirigidas a la seguridad jurídica. La teoría de la propiedad, la teoría de la adquisición y la de la justitia distributiva desarrollan los principios de la razón que, en la institución de la propiedad privada, de los contratos y de los inmuebles, en las modalidades de su adquisición y del manejo de los casos de controversia, tienen validez como postulados de la posibilidad de su existencia y como condiciones limitantes. Sin embargo, no sólo encontramos una estructura paralela del derecho privado triádico y de las tres instituciones básicas del Estado, respectivamente, en forma de silogismo, sino que Kant es unívocamente de la opinión de que la propiedad de lo mío y lo tuyo externos en sus tres posibles formas - la propiedad de cosas, la posesión del albedrío de otro por contrato y la posesión recíproca de personas en una relación cosificada-personal-, es el punto de partida y el dominio, en cierta forma el supuesto campo temático y de acción, del Estado. "Si en el estado natural no hubiese, ni siquiera provisionalmente; Mío y Tuyo externos, no habría tampoco ningún deber jurídico bajo esta relación, ni por consiguiente ningún precepto que ordenara salir de este estado." ( $(44 \mathrm{~L})$ O la siguiente formulación en el $\S 48$ : “... la voluntad del legislador (legislatoris) con respecto a lo que concierne a lo Mío y lo Tuyo externos es irreprensible..." y debe estar referida a todo el campo de la posible legislación. (Es necesario recurrir a la "Introducción a la teoría del derecho" para demostrar que el Estado también tiene competencia en el campo del cuerpo de los ciudadanos, el llamado mío y tuyo interno, como, por ejemplo, en el caso de un homicidio. Posteriormente profundizaremos en este punto, durante la discusión de la diferencia entre las jurisdicciones civil y criminal.)

Hasta aquí la idea de la razón del Estado, la teoría de los tres poderes, "que derivan de la noción de república en el sentido más lato"

12 La tríada política en la forma presentada, al igual que la teoría de la propiedad en el derecho privado, no se desarrollo sino hasta después de la Revolución Francesa, y fue presentada por primera vez en La religión dentro de los límiles de la mera razón (VI 139-142). Cfr. al respecto G. Vlachos, La penseé politique de Kant, París, 1962, 487-514. Vlachos analiza detalladamente la diferencia de la teoría kantiana respecto de la de Montesquieu, la cual acaba en un equilibrio del poder en el Estado. 
(§ 51), y su relación con el derecho privado. La idea tiene, como se dice, realidad objetiva práctica ( $\$ 51$ ); la razón, a través de un imperativo categórico, nos obliga a realizarla ( $\$ 49 \mathrm{~L})$. El siguiente paso consiste en la discusión de la cuestión de cómo se le puede proporcionar realidad a este simple ser de razón. "Pero este jefe (el soberano) no es todavía más que un ser de razón (que representa al pueblo entero), en tanto falte una persona física que represente al supremo poder del Estado y que dé a esta idea su eficacia sobre la voluntad del pueblo." ( $(51)$ La realización se lleva a cabo a través de una de las tres posibles formas del Estạdo: la monarquía, la aristocracia o la democracia, de tal manera que uno, varios o todos sean legisladores electos y le otorguen a la ley el carácter de obligatoriedad mediante el establecimiento de un gobierno, es decir, del poder ejecutivo. La teoría de las formas del Estado, en particular, es interesante dentro de la teoría del derecho kantiana, únicamente con respecto a cuán calificadas están estas formas para la realización paulatina de la idea de la república. La institución, como de hecho se presenta, puede, literalmente, ser esta o aquella forma del Estado: lo decisivo es si tiende al despotismo (especialmente a través de la eliminación de la división de los poderes) o al republicanismo. El criterio de la legislación republicana es la concordancia con el espíritu del contrato original: la idea de una legislación ejercida por el pueblo unido.

El precepto general de la legislación es el contrato original: Kant adopta la figura tradicional del derecho natural, pero la transporta del pasado al futuro. El contrato original es idéntico a l'a idea de que sólo es posible acercarse a la realidad jurídica asintóticamente; si se le ubica en nuestro tiempo, está entonces delante de nosotros, no detrás. Los actos jurídicos del presente no poseen su legitimidad según la medida de su conformidad con un testimonio histórico. Todo derecho positivo, hasia la realización de la república, es únicamente provisional y está sujeto a revisión. Las instituciones políticas deben ser comprendidas como instrumentos de la evolutio juris naturalis; su única tarea consiste en trasladar el derecho de razón de la mera idea a la realidad.

Hasta aquí la estructura básica formal de la institución política del Estado. La fundamentación en una idea de la razón práctica (¡no teórica!) significa que toda situación presente sólo puede ser tomada provisionalmente con miras a una mejor situación. Esto es válido, como se indicó al principio, tanto para la propiedad como para la constitución del Estado en su conjunto. En El conflicto de las Facultades de 1798 se afirma que es una obligación el adqui- 
rir una constitución republicana, "pero provisionalmente (porque esto no se realizará tan pronto), es deber de los monarcas, aunque reinen autocráticamente, gobernar sin embargo de un modo republicano (no democrático), es decir, tratar al pueblo según principios conformes al espíritu de las leyes de la libertad (como un pueblo con razón madura se las prescribiría a sí mismo), aunque, estrictamente tomado, a ese pueblo no se le haya solicitado su consentimiento" (VII 91, 12-18).

En unas notas sobre antropología de mediados de los años 70, cuando Kant no dispone todavía de una representación clara del concepto de razón ni de una división entre razón teórica y práctica, se concibe el desarrollo natural del Estado, según el antagonismo de fuerzas newtonianas, de la siguiente manera: "Existe entonces en el hombre un principio de sociedad, pero por otro lado existe también un principio de insociabilidad y de separación de la sociedad. Estos dos principios se contraponen, lo cual, sin embargo, fue dispuesto sabiamente por el Creador. Primeramente tienen los hombres una propensión a entrar en sociedad, pero para que la sociedad no permanezca siempre aglomerada, tienen además otro principio: el de insociabilidad, que los divide; de ahí que toda la tierra sea poblada, pues cuando en un lugar la sociedad crece demasiado, los individuos se separan y se van a otro sitio, por ejemplo, a América. Cuando ahí suceda lo mismo, volverán a separarse y a poblar nuevos países. Al final, toda la tierra será poblada. Cuando haya muchos Estados juntos, éstos se unirán y uno absorberá a los otros. Sin embargo, en cuanto éste se haya vuelto muy grande, se dividirá y sus miembros intentarán separarse. Esta es la unión y separación particular del Creador, de donde surge la diversidad y de donde posteriormente debe provenir la total perfección del género humano. Pues surgirá un método de gobierno que también permanecerá estable". ${ }^{13} \mathrm{La}$ realización de la constitución republicana, que evita por principio la guerra, sigue siendo en las publicaciones posteriores de Kant un fin de la naturaleza; sin embargo, se insiste con mayor determinación en que es una obligación de los monarcas y de los hombres en general, tender a hacer realidad el más alto bien de la política: la paz. (Cfr. especialmente VI 354-355.) Otra perspectiva histórico-filosófica es la elegida en la respuesta a la cuestión de "si el género humano se halla en constante progreso hacia lo mejor", en El conflicto de las Facultades (VII 79-94). Aquí se hace referencia decididamente a un suceso actual, la Revolución Francesa, con lo cual el término de revolución no se refiere al derrocamiento de un gobierno en el

15 Staatsbibliothek Preußischer Kulturbesitz Berlin, Ms. germ. Quart. 400, 381-383. 
poder, sino a los intentos de republicanización de los años $90{ }^{14} \mathrm{En}$ ocasión de un vacío en el poder, el pueblo francés intenta republicanizarse a sí mismo; este esfuerzo, derivado de la idea del derecho, es seguido por los demás pueblos, en calidad de espectadores, con simpatía y con un entusiasmo derivado de la idea del derecho. Ellos procurarán llevar a cabo, si se les presenta una buena oportunidad, la misma republicanización que los franceses, y por ello puede predecirse que la humanidad se dirige hacia la constitucionalidad del Estado, a cuya realización está determinada y obligada. Se puede entonces concluir que la humanidad se ha encontrado siempre en el progreso hacia el mejoramiento moral. Dado que el progreso se acelera (confiemos en ello) en la actualidad ${ }^{15}$ los días de los déspotas están contados. Así se pueden resumir las reflexiones optimistas de Kant en El conflicto de las Facultades.

Se intentó presentar la idea de la razón del Estado de Kant y mostrar de qué manera, en el acercamiento a las instituciones históricas, las cuales están siempre sujetas a poderes ilegales, se pensó en su idea legitimadora. Para concluir se harán algunas indicaciones acerca de las instituciones y organizaciones en el Estado y entre estados. Estas instituciones no corresponden propiamente al tema de una metafísica del derecho, y por ello no fueron tematizadas detalladamente por Kant. Se pueden distinguir cuatro grupos de instituciones, organizaciones o establecimientos de derecho: por un lado las organizaciones estatales del derecho público según el derecho de la razón en general, después los fundamentos del derecho privado, cuya conservación y fijación legales son obligatorias para el Estado. En tercer lugar, determinadas estructuras, digamos, entre Estado y sociedad civil, y, cuarto, la institucionalización del derecho internacional.

Los tres poderes de la legislación, el gobierno y la administración de justicia fueron deducidos como elementos necesarios de la república; Kant apenas señaló en qué forma institucional se concretizan. El parlamento, el cuerpo legislativo, sólo se menciona marginalmente. "El pueblo, que está representado por sus diputados (en el Parlamento) posee en estos guardianes de su libertad y de sus derechos, hombres..." (VI 319, 33-35). Para Kant es esencial la posibilidad de oponerse a las exigencias del gobierno

14 Cfr. al respecto, del autor, “Zum Streit der Fakultäten” en Kant-Forschungen 1 ["Sobre El conflicto de las Facultades", en Investigaciones kantianas 1], Hamburgo, 1987.

15 Acerca de la idea de Kant de una aceleración histórica, cfr. VIII 386, 2733 (la aproximación a la paz perpetua es una tarea "que, solucionada poco a poco, se acerca constantemente a su objetivo (debido a que el tiempo en el que tienen lugar avances semejantes es cada vez menor)"). 
en el Parlamento, como se establece en.la siguiente proposición: "En la Constitución de un Estado, organizada de tal suerte que-el pueblo, por medio de sus representantes (en el Parlamento) pueda legítimamente oponerse al gobierno y a sus representantes (los ministros) -Constitución que toma entonces el nombre de Constitución limitada-, no hay, sin embargo, una oposición activa (de la reunión arbitraria del pueblo, para compeler al gobierno a cierta acción y para realizar con ello él mismo un acto del poder ejecutivo), sino solamente una oposición negativa. En otras palabras, una negativa del pueblo (en el Parlamento) permite, pues, no consentir siempre a todas las demandas que el gobierno hace a nombre del Estado..." (VI 322, 4-12). Los diputados en el Parlamento son elegidos por los ciudadanos independientes y activos ( $\S 47 \mathrm{~L}$ ); sus leyes deben estar constituidas de tal manera que sean justas para las exigencias legítimas de los ciudadanos dependientes e inactivos, a saber, "el ser tratados por todos los demás según las leyes de la libertad y la igualdad naturales, como partes pasivas del Estado..., y..., que las leyes positivas que votan, cualquiera que sea su objeto, no sean jamás contrarias a la libertad natural y a esa igualdad proporcional de todos en el pueblo que permite a cada uno trabajar para elevarse de la condición pasiva a la condición activa" (VI 315, 13-22). El pueblo, como soberano, es al mismo tiempo el propietario supremo del suelo según el derecho real, y comandante supremo de sus súbditos según el derecho personal. ${ }^{16}$ En la primera función, la legislación tiene el derecho "de imponerse a los propietarios particulares del suelo, es decir, de exigir el impuesto territorial, personal, de entrada o circulación, o la prestación de servicios (tal como la leva de las tropas para el servicio militar), de tal manera, sin embargo, que el pueblo sea el que se imponga a sí mismo, porque ésta es la única manera de hacerlo legalmente, si la ,ley es obra de los diputados de la nación..." (VI 325, 10-15). Al soberano, como comandante, le corresponde el derecho de imponer a los súbditos contribuciones, "entre las cuales están el pauperismo, los asilos de beneficencia y la Iglesia, llamadas también fundaciones caritativas o piadosas" (VI 326, 1-3). El conferir cargos asalariados y honoríficos, y el derecho penal, están también sujetos a la reglamentación legal a través del comandante (VI 328, 7 y ss.). Para los

16 La misma diferenciación se encuentra en el capitulo correspondiente del Contrat rocial de Rousseau: "Du domaine réel" (I, 9): “On concoit comment les terres des particuliers réunies et contigues deviennent le territoire public, et comment le droit de souveraineté s'étendant des sujets au terrain qu'ils occupent devient à la fois réel et personnel..." La idea de un derecho apremiante y personal es entonces independiente de la idea de Kant de una especie de derecho personal cosificado en el ámbito de la casa. 
empleados públicos asalariados rige el principio de la salvaguarda de las posesiones: para garantizar la mejor ejecución posible de los quehaceres impuestos, el empleado público debe poder contar con "medios de existencia para el resto de su vida" (VI 328, 3133). Las distinciones especiales únicamente pueden ser otorgadas en razón de méritos logrados individualmente - la nobleza hereditaria constituye una anomalía heredada de tiempos pasados y debe ser eliminada gradualmente: ningún pueblo estaría de acuerdo con la introducción de una clase intermedia entre el soberano y sus súbditos (VI 328-329; cfr. VIII 433-426). El gobernador del Estado o la junta de gobierno, como menciona Kant con apoyo en la nueva constitución de Francia (VI 316, 30), impone al pueblo las normas en forma de reglamentos o decretos, según los cuales éste puede dedicarse a los negocios de acuerdo con las leyes del poder legislativo y conservar, sin lesión, lo ganado: la posesión de objetos, derechos contractuales y derechos sobre inmuebles (VI 316, 24-34).

Mientras que el derecho penal y el derecho de gracia ( $c f r$. VI 331337) radican en el soberano como comandante supremo - sobre esto ahondaremos en seguida-, la magistratura corresponde al poder del soberano y al del gobernador por separado: "El pueblo se juzga a sí mismo a través de sus conciudadanos que son libremente elegidos y que son como sus representantes; pero solamente en cada acto particular para el que han sido nombrados". Solamente de esta manera puede evitarse una posible injusticia en el veredicto, en el cual a cada quién debiera repartírsele lo suyo, según el principio del volenti non fit iniuria (VI 317, 20-36).

A la tríada política le corresponde la división del poder judicial respecto de los poderes legislativo y ejecutivo - sin embargo, Kant le adjudica el derecho penal, simultáneamente, al comandante supremo y al soberano (VI $328,13-14 ; 331,4-7$ ): una obvia contradicción en la institución de la jurisdicción en el interior del Estado. El rompimiento, que no puede ser rastreado aquí históricogenéticamente, puede ser comprendido sistemáticamente a partir de una duplicidad que yace en el fondo de la teoría del derecho kantiana. El derecho penal y el derecho de gracia se ocupan del crimen en sí, del crimen publicum frente al tribunal de lo criminal, y no del crimen privatum frente a la jurisdicción civil. El crimen publicum no se dirige contra el exterior de un ciudadano particular, sino contra el Estado en sí, e incapacita a aquel que lo comete para ser un ciudadano (VI 331, 2-11). El crimen publicum paradigmático es el asesinato y, consecuentemente, Kant se ocupa en el parágrafo correspondiente casi únicamente de la pena de muerte. El propio cuerpo no pertenece a lo mío y tuyo exterior del derecho 
privado, sino que constituye la base de cada propiedad y adquisición en general. De aquí se puede concluir: el poder judicial, en tanto se mantenga separado, como tercera instancia, de los poderes legislativo y ejecutivo, se refiere sólo al dominio de lo mío y tuyo exterior; el "suum cuique" mencionado en el texto (VI 317, 34), es exclusivamente lo suyo adquirido externamente $o$, como se dice en el ámbito de competencia de la Facultad de jurisprudencia, la "propiedad contingente" (VII 22, 11). La jurisdicción criminal que, en contra de la teoría de la división de los poderes, está en manos del soberano, no puede apartarse del derecho privado y del "exeundum est e statu naturali". arraigado en él, sino que se fundamenta, de una manera complicada, en la "Introducción a la teoría del derecho".

El Estado determina y conserva legalmente las formas de la adquisición y la posesión de lo mío y tuyo exterior; de esta manera, se convierten en dominio del Estado la posible propiedad por derecho natural, los contratos (de enajenación de propiedad, de servicios y herencias, etc.) y la institución de la finca, con sus relaciones maritales, de filiación y servidumbre. -En la esfera intermedia entre el comercio particular de los ciudadanos y los poderes del Estado, están establecidas organizaciones que surgen de los derechos y obligaciones soberanos ya mencionados: la hacienda pública y la policía (VI 325, 18-32), la Iglesia y, por lo tanto, las casas de expósitos y la ayuda a los pobres (VI 325-328). -Una última institución política: el bien político supremo es la paz; para realizarla tienen los Estados que acatar la ley del "exeundum est e statu naturali" y entrar en una asociación de Estados. Para por lo menos acercarse a esta idea, deben unirse los Estados en federaciones, en un Congreso de Estados. Con la existencia de éste, habría por lo menos un derecho internacional parcial de las naciones, "para decidir los conflictos internacionales a la manera civilizada, es decir, en forma de proceso, y no de una manera bárbara (como los salvajes), es decir, por medio de la guerra" (VI 351, 6-8).

\section{La Iglesia}

La comunidad eclesiástica es una institución contigua a la comunidad civil y Kant desarrolla muchas de sus determinaciones en una construcción paralela a esta última. Al mismo tiempo, la Iglesia es una institución política en el sentido de que el Estado tiene un interés político en su existencia y en su forma. El gobierno busca a través de las teorías públicas, en atención al bien eterno, descubrir y dirigir "hasta el más íntimo de los pensamientos y las opiniones más secretas de los súbditos" (VII 21, 27-22, 1). La Iglesia y la religión 
son, entonces, para el Estado y el gobierno una cuestión política. Sin embargo, al mismo tiempo es válido lo siguiente: "Lo único que puede interesar al Estado en materia de religión, es aquello a lo que deben atenerse los maestros de religión para formar ciudadanos útiles, buenos soldados y, en general, súbditos leales" (VII 60, 2123). Todo interés en la religión y en la teología como tales, incluso en el bienestar del alma, le está prohibido al Estado, según el principio del derecho; “... que de ningún modo es asunto del gobierno preocuparse por la felicidad futura de los súbditos y enseñarles el camino hacia ella" (VII 59, 32-35). El Estado debe ocuparse del derecho de sus ciudadanos y no de su bienestar económico y moral.

Las siguientes reflexiones llevan a Kant a admitir la necesidad práctica de una comunidad ética que, en su desarrollo concreto, se forma en la Iglesia: el hombre tiene una predisposición natural hacia el bien, que se delata en el "factum de la razón; que nos presenta el imperativo categórico como principio de juicio y de acción. Ahora bien, existe junto a este factum un hecho de naturaleza muy distinta: los hombres tienen una propensión original al mal. Kant no ve esta propensión como el efecto de nuestras inclinaciones naturales innatas, pues si el mal fuese el resultado de inclinaciones naturales superiores, entonces no podríamos ser responsables de nuestros actos - la carne se habría mostrado simplemente más poderosa que nuestro débil espíritu, que aspira a la moral. Kant reduce el mal, a pesar de designarlo como innato (puesto que está presente antes de nuestro primer acto empírico), a un acto inteligible de nuestra persona, que se evidencia en nosotros como permanentemente presente. En general, el hombre hace de la realización de los deseos de su amor propio una condición para someterse a la ley moral, en lugar de hacer de la ley la primera condición, ineludible, de su amor propio -ésta es una resolución a la que debe responder él mismo. En la inversión de las jerarquías del amor propio y la ley moral radica el absurdo del corazón, el mal radical de la naturaleza humana. Ésta es la determinación racional de aquello que en la Biblia se describe como pecado original (VI 42). La ley moral decreta, entonces, la puesta en vigor de la buena disposición natural en contra de la inclinación al mal determinada por nosotros - de aquí se desprende "la lucha del principio bueno con el malo por el dominio sobre el hombre" (VI 57, 2-3). El hijo de Dios es representado como el hombre que no sucumbe a las tentaciones y, así, por medio del ejemplo, muestra que aquello que la moralidad nos pide es de hecho realizable.

Las reflexiones de Kant, que a partir de las ideas señaladas nos conducen al núcleo racional de la teología cristiana, no pueden ser 
expuestas aquí, al igual que los razonamientos que fundamentan la introducción de la comunidad ética. El resultado decisivo es qué: "El dominio del principio bueno, en cuanto los hombres contribuyen a él, no es, pues, a lo que nosotros entendemos, alcanzable de otro modo que por la erección y extensión de una sociedad según leyes de virtud y por causa de ellas; una sociedad que se convierte, mediante la razón, en tarea y deber para todo el género humanon (VI 94, 1419).

Un segundo elemento de la argumentación (no explícitamente diferenciado del primero) se enlaza con la teología moral de la Crítica de la razón práctica (1788). Según la teoría desarrollada en esta segunda crítica, el imperativo categórico dispone que nuestras. máximas deban tener la forma de posibles leyes universales: el imperativo determina el objeto y es el móvil de la voluntad, quedándose, sin embargo, en una fijación meramente formal de la voluntad. Hace abstracción del hecho de que cada voluntad finita se refiere a un objeto de la inclinación y de la necesidad; este objeto, la materia de la voluntad moral determinada y, a la vez, de la voluntad natural, es tomado en su totalidad incondicionada, el bien supremo, el mejor mundo con una felicidad proporcianal a la moralidad. Nosotros debemos llevar a la realidad este bien supremo y, al mismo tiempo, su realización se escapa de la disposición de una mera buena intención. En este punto deduce Kant la realidad práctica objetiva del bien supremo a través del recurso a un creador sobrenatural de la naturaleza, que debe ser considerado, al mismo tiempo, como legislador moral. A esta idea, y no a las antes mencionadas, se refiere la representación de que la humanidad está determinada a la promoción del bien supremo como bien comunitario: "Pero, puesto que el supremo bien moral no se produce por el solo esfuerzo de la persona particular en orden a su propia perfección moral, sino que exige una unión de las personas en un todo en orden al mismo fin, en orden a un sistema de hombres bien intencionados, solamente en el cual, y por su unidad, puede realizarse el bien moral supremo, y por otra parte la idea de ese todo, como república universal según leyes de virtud, es una idea completamente distinta de todas las leyes morales (que conciernen a aquello de lo que sabemos que está en nuestro poder), a saber: actuar en orden a un todo del que no podemos saber si está como tal también en nuestro poder; así pues, este deber difiere de todos los otros por la índole y el principio.- Se sospechará ya de antemano que este deber necesitará del supuesto de otra idea, a saber: la de un ser moral superior mediante cuya organización universal las fuerzas de los particulares, por sí insuficientes, se unan en orden a un efecto común" (VI 97, 21-98, 12). De 
esta manera, por medio de dos ideas totalmente diferentes se deduce la necesidad de una comunidad ética bajo el dominio de Dios. ${ }^{17}$ En la segunda variante puede prescindirse de la idea particular de la teología del hijo de Dios; la comunidad ética se representa como el pueblo de Dios, cuya "Constitución" son las leyes morales.

"La idea elevada, nunca plenamente alcanzable, de una comunidad ética, se empequeñece mucho en manos humanas... ¿Cómo puede esperarse que de un leño tan torcido se produzca algo completamente derecho?" (VI 100, 22-28) En la Iglesia visible, las leyes inalterables de la Constitución se complementan por medio de determinados estatutos, que son moralmente indiferentes, pero que corresponden inevitablemente a la vida de la Iglesia. Si bien en principio es válido para toda organización eclesiástica que todos sus miembros sean libres e iguales entre sí, así como debe ser considerada libre la relación de la Iglesia con el Estado (cfr. VI 101-102), bajo el dominio de los estatutos no podrá ser evitada una cierta jerarquía. La Iglesia visible, como institución humana para la promoción de las buenas intenciones en la batalla contra el mal y para la realización del bien supremo, como lo es la unión proporcional de moralidad y felicidad, reúne consecuentemente dos componentes en sí misma: la fe racional, que se refiere exclusivamente a la legislación moral reconocible a priori, y la fe en la Iglesia, que contiene en las instituciones humanas estatutos y ritos ineludibles. El origen de la razón, que representa al mismo tiempo el objeto y el fin históricos de la institución, radica en la moral; por el contrario, históricamente la Iglesia se origina, como lo demuestra el judaísmo, únicamente con estatutos y leyes externos. La observancia de lo externo es necesaria para la "introducción" de la comunidad ética, así como en la historia política el poder constituye el origen del derecho. El énfasis de la teoría eclesiástica kantiana está puesto en la tesis de que la fe estatutaria en la Iglesia debe ser reducida y finalmente eliminada del todo, conforme los hombres vayan alcanzando la madurez. Lo que tenía una función provisional y necesaria en la primera fase de la educación moral de la humanidad se convierte, conforme progresa la conciencia, en una atadura. La administración humana, el clero, desarrolla una dinámica propia e intenta sustituir la moralidad por observancias arbitrarias, como la asistencia constante a la iglesia, y determinadas fórmulas de oración y de enviar, como los tibetanos, sus deseos "a través de la rueda de la oración ante la autoridad divina" (VI 103, 10). De esta manera, se repite

17 No conozco ninguna interpretación de la filosofía de la religión de Kant que distinga las diversas fundamentaciones de la Iglesia. Informa detalladamente J.-L. Bruch, La philosophie religieuse de Kant, París, 1968. 
en la Iglesia misma, en cierta medida, la batalla del principio bueno de la legislación moral contra el principio malo: de este lado la fe racional pura con los principios de la moralidad, y de aquél, la fe en la Iglesia con los estatutos que tratan de colocarse en el lugar de la moralidad. La teoría institucional generalizada indica que lo que bajo ciertas condiciones históricas fue necesario, se transforma, después de que ha perdido su función, en una fuerza contraria que se opone al fin original.

\section{La Universidad}

Kant no era ciudadano de la ciudad de Königsberg (contrariamente a su sirviente Lampe), sino ciudadano de la Universidad Albertus. Nó depositó su testamento del 27 de febrero de 1798 ante el tribunal de la ciudad, sino ante el senado académico de la Universidad. A ésta, su polis, le dedicó en la vejez una teoría de "la autoafirmación de la Universidad", escrita contra las presiones del régimen oscurantista despótico de Federico Guillermo II: el "kingdom of darkness" amenazaba con devorar a la Institución de la Ilustración, la Universidad, y Kant intentó erigirle un paladión. ¿Cómó se llega a la institución de la Universidad y bajo qué puntos de vista se desarrollan el cambio y la conservación de su organización? El conflicto de las Facultades, que anuncia el título de la obra de 1798, es legitimado teóricamente en la "Introducción": Kant intenta mostrar cómo el conflicto entre las Facultades superiores (Teología, Jurisprudencia, Medicina) y la Facultad inferior (Filosofía) está basado en los principios racionales o la "idea racional" de la Universidad (VII 21, 6; cfr. XXIII 430, 21-22: "Idea de una Universidad"). La idea racional, en el sentido kantiano, garantiza que la teoría en ella basada no se transforme ni en una simple utopía y una organización ficticia de eruditos [Gelehrten], ni copie a la universidad histórica, sino que funde una institución conforme a determinados principios racionales y necesidades reales, en la que se reconozcan las universidades existentes no del todo abandonadas por la razón, y a la que puedan y deban ser adaptadas. Esto mismo era válido para las instituciones del Estado y de la Iglesia basadas en ideas racionales.

Así como la fundación de Estados está basada en el interés vital de los hombres, por no permanecer en estado natural (VI 311), así también conforman la base de la Universidad determinados intereses de los ciudadanos. Estos intereses son de tres tipos, de acuerdo a la tríada que ya conocemos de alma, cuerpo y bienes materiales. Cada hombre se preocupa por el bienestar de su alma, su salud y la conservación de la "propiedad contingente" (VII 22, 11). Los 
intereses así estructurados conforman la base de un cálculo político del gobierno: por medio de las teorías públicas y en atención al bienestar del alma "el gobierno puede tener la mayor influencia hasta sobre el más íntimo de sus pensamientos y las opiniones más secretas de los súbditos, para descubrir los primeros y dirigir a los últimos"; por medio de la administración de la salud puede "asegurarse la existencia de un pueblo fuerte y numeroso que pueda servir a sus intenciones", y a través de la garantía de los bienes legales respecto de terceras personas puede mantener la conducta exterior de los ciudadanos "bajo el freno de las leyes del Estado" (VII 21, 27-22, 5). Para tal fin sirven las Facultades de Teología, Medicina y Jurisprudencia. Ellas fundan en obras, como dice Kant, la teoría a ellas encomendada por el Estado: en el caso de la teología, en la Biblia; el jurisconsulto se apoya en el derecho civil, y el médico se rige por el reglamento médico (VII 22-23).

No así la Facultad inferior, la de Filosofía, contrapuesta a las tres Facultades superiores. Ésta no está orientada hacia ningún interés particular de los ciudadanos, no está ligada a ninguna obra canónica y no está sometida a autoridad gubernamental alguna, sino que obedece únicamente a la razón en su (interesada) desinteresada búsqueda de la verdad. "Es absolutamente necesario que en la Universidad la institución cientffica pública posea otra Facultad que, independientemente de las órdenes del gobierno en lo que se refiere a sus doctrinas, tenga la libertad, si no de dar órdenes, al menos de juzgar a todas las que se interesan por la ciencia, es decir, por la verdad, y en que la razón tenga el derecho de hablar con franqueza; porque sin esta libertad la verdad no podría manifestarse (lo que va en perjuicio del gobierno mismo), pues la razón es libre por su naturaleza y no acepta órdenes que le impongan tomar por cierta tal o cual cosa (ningún crede, sino simplemente un credo libre)" (VII 19, 21-20, 6).

Con esto se introduce, en la institución universitaria un contraste en principio irrevocable: las Facultades superiores ejercen las disciplinas que responden a intereses y que están dogmáticamente atadas, para formar empleados públicos que se ocupen del bienestar corporal y espiritual y de la integridad de los bienes de los ciudadanos; la Facultad inferior ejerce la crítica al cuerpo de profesores en tanto que utiliza la verdad de la razón y de la experiencia contra los dogmas. El gobierno, paradójicamente, también está interesado en que exista la búsqueda desinteresada de la verdad, al igual que un Estado libre de prejuicios se interesa por una economía no dirigida por él, sino dirigida según principios liberales. "Laissez faire, laissez aller": ésta sería la respuesta "que tendría que dar la Facultad de 
filosofía, si el gobierno le pidiera informes sobre las doctrinas que tendria que prescribir en general a los letrados: únicamente no poner trabas al progreso de las luces y de las ciencias" (VII 20, 13-16). Por lo tanto, Kant no vincula el conocimiento libre, institucionalizado por el gobierno, a temas que prometen una utilidad inmediata (como la economía, la ciencia agrícola, la minería), sino que deja totalmente abierța la cuestión relativa a los objetos de la investigación racional e histórico-filosófica. Únicamente postula que el gobierno garantice la libertad de investigación y cátedra en la Universidad: únicamente por medio de una búsqueda alerta de la verdad y del conocimiento, libre de toda tutela gubernamental y puesta en marcha mediante la filosofía, puede realizarse verdaderamente el interés gubernamental - que no tiende a la verdad, sino a la utilidad.

Según la "idea racional" kantiana, la Universidad constituye una comunidad culta dentro de la comunidad civil y copia la estructura política de la república, de cuyo sistema forma parte. Al mismo tiempo, presenta miméticamente dos fases del desarrollo moderno. Por un lado, el orden de precedencia de arriba y abajo es la imitación y la recepción sistemática de la organización tradicional de jerarquía y clases que se basa en la inalterable estructura espacial de cielo y tierra. La Universidad imita, con su jerarquía de Facultades, la relación de regente y "súb"-dito, de amo y esclavo. Esta organización de clases es contrarrestada por el segundo concepto subjetivo, basado en el propio cuerpo, el concepto de derecha-izquierda, el cual fue puesto en circulación dentro del orden político con la Revolución Francesa. Este concepto de derecha-izquierda se vuelve intercambiable con el esquema del tiempo, con su aspecto dual de pasado y futuro: se enfrentan partidos de derecha en el poder y partidos de oposición de izquierda (VII 35, 1-7); la derecha conservadora vela por la conservación del grupo de profesores, la izquierda progresista vela por el "progreso de las luces y de las ciencias" (VII 20, 15-16). Aquí se enseñan y difunden los dogmas sancionados por el gobierno, allá se revisan, se corrigen y se amplían los presuntos conocimientos, sin dogmatismo y según los principios de "igualdad y libertad" (VII 23, 18); de este lado, el gobierno con la salvaguarda de la tradición, del otro lado, el liberalismo orientado hacia el futuro en la búsqueda de la verdad.

De esta manera incorpora la Universidad el motivo del antiguo orden espacial estático y del nuevo esquema temporal, y los refleja en la dialéctica de la conservación y la innovación.

Si se abandona el plano de la interpretación dirigida a la objetividad y se prescinde de la adhesión kantiana al orden de las cuatro Facultades, se puede rescatar de la teoría de la Universidad 
un programa científico-metodológico: el conocimiento científico, en general, opera entre los polos de la conservación de la enseñanza, que está marcada de modo consensual como estado actual de la investigación y se publica en los libros de texto, y la investigación renovada de la naturaleza de las cosas, en la cual los dogmas se muestran falsos, redundantes o demasiado poco complejos. La innovación, que engendra el progreso del conocimiento y de las ciencias, puede, entonces, por su lado, enriquecer o sustituir la estabilidad de los dogmas a través de la arbitrariedad reglamentada del consenso. Los papeles que Kant atribuye casi siempre por separado a las dos clases de personas cultas de las Facultades superiores y de la Facultad inferior, muestran el doble papel que ha de jugar cada científico.

Kant distingue entre un conflicto ilegal y uno legal de las Facultades superiores con la inferior (VII.29-35). En la situación del conflicto ilegal, el lector reconoce sin dificultades la situación que motivó a Kant a elaborar su teoría de la Universidad; está caracterizada por la intervención del gobierno en el conflicto intrauniversitario. ${ }^{18}$

El contraste entre un conflicto legal y uno ilegal nos recuerda, al mismo tiempo, una representación kantiana más antigua, que tal vez exhiba el modelo de las dos formas de conflicto: así como la comunidad culta es concebida antagónicamente, así concibe Kant, ya en los años cincuenta, la materia como conflicto de dos fuerzas contrastantes. El desarrollo del cosmos conforme a leyes, se efectúa sobre la base de fuerzas contrapuestas; una ilegalidad sólo puede tener lugar si Dios no se da por satisfecho con el papel de inaugurador de los sucesos mundiales, ssino que interviene y cree que debe hacer correcciones por medio de milagros. Según el mismo esquema, el conflicto ilegal es concebido como una disputa, en la que la Universidad no es abandonada a sus propias fuerzas, sino que se ve apartada de su cauce normal por la intervención del gobierno.

La institución política de la Universidad sólo puede cumplir apolíticamente con su tarea -éste es el pensamiento kantiano de la "autoafirmación de la Universidad".

\section{La libertad de publicación}

Iniciamos nuestras exposiciones con la idea de Kant de que se puede "mirar la Crítica de la razón pura como el verdadero tribunal para todas las controversias de esta facultad"; ella estaría puesta para

18 Para el texto y la interpretación de El conflicto de las Facultades, cfr. la publicación mencionada en la nota 14. 
"determinar y juzgar los derechos de la razón en general, según los principios de su institución primera". La contraparte empírica de este tribunal es "el tribunal del juicio público". 19 "...dado que el hombre podría equivocarse plenamente en sus juicios particuilares y vivir el sueño de la total comprensión, la naturaleza puso al público como el legítimo juez de nuestros pensamientos; la razón humana general debe dictar la sentencia cuando un individuo haga uso particular de la razón..., ya que no se puede integrar la verdad de otra manera más que un hombre juzgue al respecto, comunique este su juicio a otros hombres, para lo cual la prensa rotativa le ofrece una cómoda posibilidad, ya que por este medio se ilustra al público", reza el texto de una nota de las lecciones kantianas sobre antropología. $^{20}$ (Una reflexión ilustrativa: antes del inicio de la Edad Moderna podría lograrse el consenso para la confirmación de la certeza subjetiva de la verdad a través de la apelación a las autoridades; citar a Aristóteles puede servir como comprobación de que una determinada doctrina no se basa en una idiosincrasia. Para el autor moderno, convencido del progreso del conocimiento, la autoridad de una época anterior no puede cubrir la necesidad de consenso; él tiene que salir al encuentro del juicio de autores contemporáneos, lo cual sólo puede lograrse por medio de una prensa rotativa libre. (En cuanto la fe en el progreso decrece, surge una historización y relativización de todas las instancias de comprobación.) -Y: el producto de la búsqueda de conocimiento tiene que acreditarse en

19 Esta formulación, que podría sin duda provenir de Kant, la utiliza Johann Heinrich Campe en una carta del 10 de septiembre de 1791 al duque de Braunschweig; citado según P. Weber, Die berlinieche Monateschrift alo Organ der A ufklärung [La Berlinische Monatsschrift como órgano de la Ilustración], en Berlinioche Monateschrift (1789-1796)... Selección, Leipzig, 1986, 436.- Este tribunal no debe ser confundido con la "opinión pública" o la "opinión popular" (VI 224, 31-32 y 235, 2), que apoya, por ejemplo, las instituciones feudales ilegales.Una colección de los puntos pertinentes al tema "publicidad" se encuentra en J. Habermas, Strukturwandel der Öffentlichkeit. Untersuchungen zu einer Kategorie der bürgerlichen Gesselschaft [Transformeción estructural de la publicidad. Investigaciones acerca de una categoría de la cociedad civil], Neuwied, 1962, 118-132.

20 Immanuel Kanto Menschenkunde oder philosophische Anthropologie [Tratado del hombre - antropología filosófica de Emanuel Kant], editado por F. C. Starke (= J. A. Bergk), reimpresión de la primera edición de 1838, Hildesheim y Nueva York, 1966, 34-35. La Anthropologie-Leningrad [Antropología-Leningrado], sin fecha (hasta ahora inédita), en lugar de la cita sin sentido "als daß ein Mensch darüber urtheilt, dieses sein Urtheilt..." ["más que un hombre juzgue al respecto, [comunigue] este su juicio..."], dice: "als bis ein Mensch der über etwas urtheilt, diejes sein Urtheil..." ["sino hasta que un hombre gue juzga sobre algo, [comunigue] este su juicio..."] (p. 21). -Acerca de la razón humana universal, el koinos nous, cfr. XXIV 93, 13-26; 391, 1-6; 721, $35-38 ; 874-875$; II 334, 11-24; 342, 16-26; XV 632-633 (Reflexiones 1448a); $\mathrm{XX} 179,1$. 
el mercado libre; David Hume es acaso el primer filósofo que debe su manutención a la prensa libre y al comercio del genio; con ello se vuelve obligatoria también para el investigador académico la acreditación ante el juicio de cualquier lector culto, que sólo es alcanzable por medio del mercado. -En Kant no se descubre ninguna reflexión en este sentido.) La institución de este tribunal empírico se basa en un derecho: "No se debe, entonces, poner ningún obstáculo a la publicación de los juicios, es decir, a la exposición de los puntos de vista. Éste es el derecho universal de cada hombre y la única vía segura de llegar a la verdad" (XXIV 93, 13-16).

David Hume habla de la libertad de prensa como un "common right of mankind", y la idea de Kant acerca del derecho de publicación parece estar basada, de manera similar, en una idea de humanidad. En la Antropología desde el punto de vista pragmático de 1798 dice, bajo el título de "El carácter de la especie": "El hombre está determinado por su razón a estar en sociedad con hombres, y a cultivarse en ella mediante el arte y la ciencia, a civilizarse y moralizarse, a no abandonarse pasivamente, por grande que pueda ser su inclinación animal, a las incitaciones de la comodidad y de la vida regalada, que él llama dicha suprema, sino más bien a hacerse, en la lucha con los obstáculos que dependen de la crudeza de su naturaleza, digno de la humanidad" (VII 324, 35-325, 4). Sin conocimiento científico no son posibles la cultura, la civilización o la moral; cuando el control de las propias convicciones, ejercido por los juicios de otros, es parte del conocimiento, entonces la libertad de publicación, que es la única que hace posible este control, es un elemento indispensable para el progreso del destino de la humanidad. En vista de que el Estado mismo está sujeto a este destino, no está facultado para evitar la libertad de publicación. ${ }^{21}$

La libertad de publicación es el medio a través del cual las instituciones del Estado, la Iglesia y la Universidad se liberan paulatinamente del yugo del poder, de la simple obediencia externa a las leyes y de la escolástica, y se acercan a su idea racional.

No me parece posible considerar que el derecho de publicación de Kant está basado en un "deber individual de utilizar el juicio de los demás como un criterio externo de la verdad", como supone $N$. Hinske ("Pluralismus und Publikationsfreiheit im Denken Kants" ["Pluralismo y libertad de publicación en el pensamiento de Kant"), en Meinungsfreiheit-Grundgedanken und Geschichte in Europa und USA [Libertad de opinión-Ideas fundamentales e historia en Europa y EUA], editado por J. Schwartländer y D. Willoweit, Kehl y Strassburg, 1987, 31-49 (46). Ninguno de los pasajes empleados por Hinske (loc. cit., 47) dice que exista un deber de tal naturaleza. 
1. La publicación de ensayos de filosofía del derecho es un correctivo esencial del derecho positivo, el cual requiere de ilustración para liberarse de los residuos del poder original. "Así pues, la libertad de la pluma - dentro de los límites del respeto y el amor a la Constitución en la cual se vive, mantenida por el pensamiento liberal de los súbditos, que además ella misma inspira (y con ello se autolimitan también las plumas entre sí, para no perder su libertad) - es el único paladión de los derechos del pueblo." (VIII 304, 15-20) ${ }^{22} \mathrm{La}$ catarsis del derecho se hace efectiva a través de las publicaciones cultas acerca de los principios que sirven de base al Estado y sus instituciones y cuya legitimación radica en su puesta en vigor (en lugar de en acuerdos anteriores).

Kant no sólo le niega al Estado al derecho de impedir la libertad de publicación, sino que ve realizado, en su autorización, el beneficio propio del Estado: un gobierno que comprende su legítimo interés encuentra "en la libertad de la Facultad de filosofía y en la ilustración que de ésta recibe, más fácilmente que en su propia autoridad absoluta, los medios para alcanzar sus fines" (VII 35, 2527). Y, en tercer lugar, las propias medidas tomadas por el gobierno están bajo el criterio y el mandato de la publicidad. En la obra Para la paz perpetua, de 1795 , en el ensayo "Acerca de la unanimidad de la política con la moral según los conceptos trascendentales del derecho público" (VIII 381, 3-4) se desarrolla la siguiente "Fórmula trascendental del derecho público" (VIII 381, 22): "Todos aquellos actos referentes al derecho de otros hombres, cuyas máximas no sean compatibles con la publicidad, son injustos" (VIII 381, 24-25). $Y$, en una variante positiva: "Todas aquellas máximas que requieran de la publicidad (para no errar su objetivo), concuerdan con el derecho y la política unidos" (VIII 386, 12-13). La transparencia de la política vela por su legalidad.

2. Uno de los conceptos rectores de la filosofía de la religión de Kant es el de la comunicabilidad pública. Quiero, por lo pronto, mostrar brevemente en qué contexto se transforma este concepto en un término técnico en Kant y, acto seguido, exponer su función en el campo de la fe en la Iglesia y la fe racional.

En una carta del primero de julio de 1794 dirigida a Jacob Siegismund Beck, escribe Kant: "Sin embargo, nosotros sólo podemos comprender y comunicar a otros aquello que podemos hacer nosotros mismos..." (XI 496). Este "hacer" es, en el conocimiento, esencialmente la integración. "No podemos ver la integración como 
algo dado, sino que debemos llevarla a cabo nosotros mismos: tenemos que integrar, si hemos de representarnos algo integrado (incluso el espacio y el tiempo). Con base en esta integración podemos entonces comunicarnos entre nosotros." (XI 496) No se puede comprender una cosa como una percepción simplemente dada, como, por ejemplo, una sensación; es sólo la construcción de un conocimiento a partir de un material dado la que puede ser expresada en forma de reglas y reproducida por aquellos a los que les comunicamos esa construcción. Un comunicado, entonces, en el sentido enfático del término, sólo es posible si el propio sujeto receptivo es capaz de llevar a cabo el acto de conocimiento que le fue comunicado. $^{23}$

La idea de la comunicabilidad es, para recordarlo aquí rápidamente, constitutiva para la teoría kantiana de lo bello; lo bello es objeto de un juicio de gusto, y del gusto estético se dice que se podría "definir como la capacidad de juicio de aquello que hace universalmente comunicable nuestro sentimiento respecto de una determinada representación, sin la mediación de un concepto" (VI 295, 27-29). Cuánta energía posee para Kant el concepto de la comunicabilidad lo muestra el final de la Crítica de la facultad de juzgar estética, en el que el arte griego se presenta como "arte de la comunicación recíproca de ideas" (V 355-356).

La Iglesia tiene su origen histórico en una supuesta revelación dada a la humanidad, y en ceremonias exteriores; su origen racional y su finalidad histórica radican, por el contrario, en la fe moral pura, que se refiere a Dios como apoyo en el combate contra el mal y como ayuda para la realización del bien supremo. El origen histórico de la Iglesia, en el esquema dispuesto por Kant, es lo meramente privado, aquello que divide a la humanidad; en cambio, en la fe racional radica aquello que es capaz de una comunicación pública universal (en el sentido enfático de la palabra). Es esta fe la que nos conduce a la fundación de un reino noral, "lo cual afirma el triunfo sobre el.mal y asegura al mundo, bajo el dominio del principio bueno, una paz eterna" (VI 124, 3-5). La supuesta revelación dada a los hombres debe, para poder calificar para la moralidad universal, estar constituida de tal modo "que los hombres, por el mero uso de su razón, hubieran podido y debido llegar por sí mismos a ella" (VI 155, 31-33) — sólo con esto está asegurada la comunicabilidad de la fe. "De acuerdo con esto es injusto prohibir en el Estado que los hombres escriban libros, y deban juzgar algo, por ejemplo

23 Cfr. también el final de la Deducción Trascendental de la Crítica de la razón pure de 1787 (B 168) y V 384, 4-6 (“... pues s6lo se puede comprender cabalmente tanto como puede hacer y crear uno mismo a voluntad"). 
sobre cuestiones religiosas. .. " dice consecuentemente en la llamada Lógica vienesa fechada alrededor de 1780 (XXIV 874, 35-37).

3. La Universidad vive, como lo demuestra Kant en la Introducción de El conflicto de las Facultades, de la libre expresión pública de la opinión de los eruditos no en forma de "pláticas interdisciplinarias", sino a través de publicaciones que se dirigen a los eruditos en general.

Con esto llegamos al final de la cuadratura de las "instituciones" kantianas. Las organizaciones artificiales del Estado, la Iglesia y la Universidad están basadas en ideas racionales, modelos básicos reconocibles a priori conforme a los cuales los rituales históricos que tienen un poder ilegal, meramente exteriores pero declarados esenciales, y las estructuras históricas deformadas por un dogmatismo impuesto, pueden ser corregidos. El fermento de la aproximación a la idea es la libertad de la pluma (culta), a cuya prohibición no puede estar autorizado Estado alguno. La libertad de publicación garantiza la legalización paulatina de las relaciones de poder del Estado; la comunicabilidad pública es criterio de la razón en asuntos de fe, y la Universidad únicamente puede cumplir su idea a través de la publicación de la opinión y la crítica cultas, libres de toda censura por parte del Estado.

TRADUCCIÓN DE RICARDo HORNEFFER 